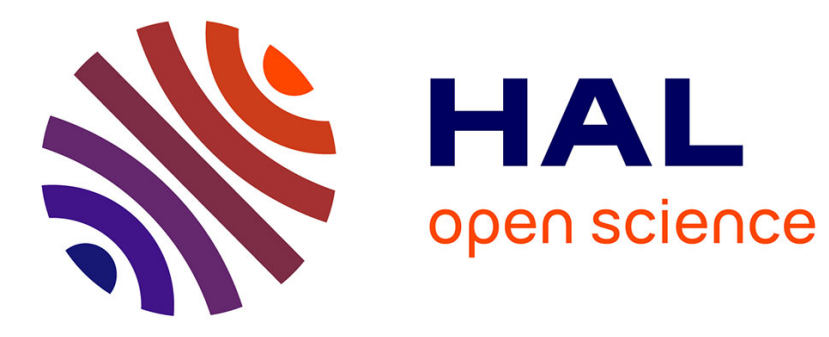

\title{
Informatics Teachers' Self-efficacy - A Survey Instrument and First Results
}

\author{
Claudia Hildebrandt
}

\section{To cite this version:}

Claudia Hildebrandt. Informatics Teachers' Self-efficacy - A Survey Instrument and First Results. 11th IFIP World Conference on Computers in Education (WCCE), Jul 2017, Dublin, Ireland. pp.536546, 10.1007/978-3-319-74310-3_54. hal-01762879

\section{HAL Id: hal-01762879 \\ https://hal.inria.fr/hal-01762879}

Submitted on 10 Apr 2018

HAL is a multi-disciplinary open access archive for the deposit and dissemination of scientific research documents, whether they are published or not. The documents may come from teaching and research institutions in France or abroad, or from public or private research centers.
L'archive ouverte pluridisciplinaire HAL, est destinée au dépôt et à la diffusion de documents scientifiques de niveau recherche, publiés ou non, émanant des établissements d'enseignement et de recherche français ou étrangers, des laboratoires publics ou privés.

\section{(c)(1)}

Distributed under a Creative Commons Attribution| 4.0 International License 


\title{
Informatics Teachers' Self-Efficacy - a Survey Instrument and First Results
}

\author{
Claudia Hildebrandt \\ University of Oldenburg, Computer science education research group, Germany \\ claudia.hildebrandt@uni-oldenburg.de
}

\begin{abstract}
The general concept of self-efficacy is based on the individual's own perception of being capable to handle challenging professional situations, for example in the fields of scientific knowledge, pedagogic expertise and conflict management. By means of existing literature, a questionnaire has been created to measure different aspects of self-efficacy in German informatics teachers as well as professional overload. Completed questionnaires of 58 informatics teachers have been analysed to investigate their perceived general self-efficacy and their informatics-specific self-efficacy. The results suggest that the majority of the surveyed teachers have a relatively high self-perceived overall self-efficacy and don't feel professionally overloaded. In contrast to other studies, this investigation determines no correlations between informatics teacher's general self-efficacy and their ratings of professional overload. However, there is only evidence for medium negative coherence between informatics teacher's self-efficacy in a very subjectspecific area of informatics and professional overload.
\end{abstract}

Keywords: Self-efficacy, Social cognitive theory, Teachers' self-efficacy, Computer science education, Empirical study.

\section{Introduction and motivation}

Teachers must meet several very different expectations: e.g. structuring teaching lessons properly regarding educational content with consideration of didactical elements to increase student's motivation, offering differentiated support and showing assertiveness not only during conflict situations. To accomplish these methodicaldidactical, professional and pedagogical requirements, a high level of individual belief in own capabilities, the so-called expectation of self-efficacy, is necessary. The perceived self-efficacy is known to influence perception, motivation and performance as well as acting habits [4]. Following this approach, this paper is focused on the theoretical background of the self-efficacy theory and its importance in the school field (cf. chapter 2). Specifically, professional overload, the individual teacher's selfefficacy and informatics-specific self-efficacy, particularly in the area of automated processes, are investigated and considered in the following structure. In chapter 3 the research issues are described and a description of the applied constructs is given. Furthermore, the designed questionnaire and its utilisation for the collection of quantitative data are introduced in chapter 4 . The preliminary results, which refer to the research questions, are outlined in chapter 5. 


\section{Background and related work}

The scientific foundation for the present work is the concept of self-efficacy, which was developed in the context of clinical psychology by Albert Bandura [2] in the 1970s. This concept has gained in importance within several recent studies of empirical educational research [17]. Bandura defined self-efficacy as the belief about one's own capabilities to organize and execute a certain task. Furthermore, Bandura assumed that "expectations of personal efficacy determine whether coping behaviour will be initiated, how much effort will be expended, and how long it will be sustained in the face of obstacles and aversive experiences” [2, p. 191]. Efficacy beliefs, which are defined as the "beliefs in one's capabilities to organize and execute the courses of action required to manage prospective situations” [3, p. 2], affect the thoughts, feelings, personal motivation and actions. These beliefs may contribute significantly to attainments and human motivation [3, p. 3]. Following the explanations by Bandura, the individual self-efficacy of teachers is defined as the conviction and expectation of being able to use one's own abilities and resources to handle specific challenging professional situations successfully.

This concept of individual self-efficacy of teachers is to distinguish from their individual self-concept: "In very broad terms, self-concept is a person's perception of himself.” [17, p. 411] Both constructs, self-concept and self-efficacy, are similar in cases of the centrality of perceived competence in construct definition, whereby mastery experience serves as main information source as well as social comparisons, and appraisals. To assess the constructs of self-concepts, contextual information is negligible, whereas when self-efficacy is determined the achievement of specific goals within given circumstances is substantial. The assumption of a teacher of being able to teach e.g. certain sorting algorithms in a student-orientated way, is a selfefficacy expectation, but gives no declaration about the competence of the teacher to convey every kind of algorithm in this way (self-concept). Further differences and information concerning self-efficacy and self-concept can be found in [7].

The results from the self-efficacy research of the last 40 years suggest that a teacher's high level of occupation-specific self-efficacy corresponds positively with the quality of classroom processes (instructional support, classroom organisation, emotional support), with students' academic adjustment (academic achievement, student motivation) and, not least with the teacher's well-being ([4, p. 240 - 243], [17]). Gibson and Dembo [10], who investigated elementary school teachers, found that teachers with a high sense of instructional efficacy and strong beliefs in their ability to promote learning, devote more classroom time to academic activities, provide students, who encounter difficulties, with the guidance they need to succeed, praise their academic accomplishments, and create master experiences for their students. In contrast, teachers with a low perceived efficacy and self-doubts about their instructional efficacy spend more time on non-academic pastimes, readily give up on difficult students, criticize them for their failures, and construct classroom environments that are likely to undermine students' judgments of their abilities and their cognitive development time.

In a German pilot experiment at ten schools from 1995 - 1998 a common goal was to increase the level of self-efficacy among students and teachers. It was shown that a teacher's high degree of vocational-specific self-efficacy had a positive health effect 
and could be considered as a preventative factor for example against the burn-out syndrome ([16], [15]).

The number of the research projects on factors that influence the teacher's selfefficacy in daily school life is limited [9, p. 9f]. By considering the collected data of 50 elementary and secondary school teachers, Santos and Pedro [14] concluded that ICT $^{1}$-training presents significantly positive effects on teachers' level of computers self-efficacy and the level of ICT use in classrooms. In a longitudinal study, Holzberger, Philipp, and Kunter investigated how teacher's self-efficacy may be related to instructional quality. Amongst other things, they found that an increase in self-efficacy relates to experiences of success in the classroom [11]. From 2003 to 2008, during the model project, at independent schools in North Rhine-Westphalia, Germany, Gebauer investigated determinants of the teachers' self-efficacy beliefs. One of her central conclusions was that the teacher's affective and emotional current state shows the strongest and most stable correlation to their self-efficacy beliefs. Therefore, this current state is an essential source to acquire the belief in one's selfefficacy in a teacher's everyday school life. Her scales for measuring job satisfaction and the situation of the working atmosphere serve as indicators of this source - the affective and emotional state [9, p. 139]. Following this approach, professional overload is one investigated indicator in this survey.

\section{Research questions}

Based on Bandura's theory of self-efficacy, this survey may help to investigate different forms of teachers' self-efficacy. It is intended to compare the obtained results with the results of the study of [16], who investigated individual teacher's selfefficacy in different types of teachers. The main research questions are the following:

1. How do informatics teachers rate their individual self-efficacy as a teacher and their professional overload compared to the results of Schwarzer/Jerusalem [16]?

2. How do teachers rate their individual teacher's self-efficacy in the subject informatics and their individual teacher's self-efficacy in the subject area automated processes as well as their general subjective teaching competence in informatics (their self-concept in teaching informatics in general) and in automated processes (their self-concept in teaching automated processes) at the beginning of a further teacher training?

3. To what extent do individual teacher's self-efficacy, general informatics-specific self-efficacy, subject-specific self-efficacy in automated processes, professional overload, general teaching competences in informatics and teaching competence in automated processes correlate?

\subsection{Definitions of constructs}

To gain information about the teachers' perceptions the following constructs are used: Individual teacher's self-efficacy: This construct measures the teacher's belief to master a general challenging professional situation with the help of own capabilities

1 Information and Communication Technologies (ICT) 
and resources. For example, the success in creating learning environments to develop students' cognitive competences bases, according to Bandura [4, p. 240], not only on the talent, but also on the self-efficacy.

General informatics-specific self-efficacy: The construct includes the belief of a teacher to master general informatics-specific and challenging professional situations with the help of his/her capabilities and resources. Certain aspects that belong to the educational contribution of the subject informatics to the general education can be recorded with this construct.

Subject-specific self-efficacy: The construct is based on the belief of a teacher to master informatics-specific challenging professional situations with own capabilities and resources. In this investigation only the area of automated processes is considered. Automated processes contain autonomously working technical systems, which change their states with the aid of an information processing unit. For instance, this area includes the construction and implementation of a robot as a simple informatics system. This system controls the actuators with sensors and processing components. The step-by-step formulated instructions should be implemented as an algorithm.

Professional overload: This construct reflects the perceived occupational strain of a teacher in general.

An overview of the constructs, their reliability and exemplary items can be found in Table 1.

Table 1. Overview of the constructs, number of items $\mathrm{n}$ and Cronbach's Alpha $\alpha$

\begin{tabular}{|l|l|l|l|}
\hline Construct & $\mathbf{n}$ & $\boldsymbol{\alpha}$ & Example items \\
\hline $\begin{array}{l}\text { Individual teacher's } \\
\text { self-efficacy }\end{array}$ & 10 & 0.752 & $\begin{array}{l}\text { I know that I can keep in good contact with the parents } \\
\text { even in challenging situations (WIRKLEHR_02). } \\
\text { I am sure that I can deal with the students' individual } \\
\text { problems very well (WIRKLEHR_04). }\end{array}$ \\
\hline $\begin{array}{l}\text { General informatics- } \\
\text { specific self-efficacy }\end{array}$ & 8 & 0.884 & $\begin{array}{l}\text { I know that my informatics lessons enable the students } \\
\text { to handle informatics systems reflectively and } \\
\text { responsibly. }\end{array}$ \\
\hline $\begin{array}{l}\text { Subject-specific self- } \\
\text { efficacy (automated } \\
\text { processes) }\end{array}$ & 5 & 0.866 & $\begin{array}{l}\text { I know that I am able to impart students the competence } \\
\text { to develop an algorithm to control a simple informatics } \\
\text { system. }\end{array}$ \\
\hline $\begin{array}{l}\text { Professional } \\
\text { overload }\end{array}$ & 6 & 0.740 & $\begin{array}{l}\text { I often feel overburdened (BEL_09). } \\
\text { I often have a bad conscience towards the students } \\
\text { (BEL_12). }\end{array}$ \\
\hline
\end{tabular}

\section{Research method}

\subsection{The measurement instrument}

This chapter describes the development of the questionnaire. In a first step, all items of the defined characteristics were determined. In the selection of the constructs' items individual teacher's self-efficacy and professional overload already existing 
scales were used. The items have been adopted nearly unchanged from Schwarzer and Jerusalem [16]. Their individual teacher's self-efficacy included areas with different competence requirements of teachers like social interactions with students, parents, colleagues, and coping with stressful professional situations [16, p. 60]. Minor changes have been implemented to some items: "I can enforce changes within the model project over sceptical colleagues." was changed into "I can enforce changes within the school-internal curriculum over sceptical colleagues.” (WIRKLEHR_10). One of Gebauer's results was that the affective and emotional state is a dominant source in order to acquire the belief in one's own self-efficacy as a teacher (see section 2, [9, p. 139]) in everyday school life. Therefore, professional overload is one investigated indicator. The scale for professional overload has been adopted from [16, p. 73]. The outcomes of Schwarzer's and Jerusalem's first data collection with 273 teachers are relatively old. However, more recent data for these constructs are not available. Consequently, the results of Schwarzer and Jerusalem are compared with the ones described here.

In the development of the constructs general informatics-specific self-efficacy and subject-specific self-efficacy the indicators' requirements analysis was done under consideration of the core curriculum for informatics for the classes 5 to 10 of all secondary school types in Lower Saxony from August 2014 [13]. With a compact measuring instrument, the general informatics-specific self-efficacy has been collected. It embraces the contribution to education, which the subject informatics must fulfil. For example, "Even though I make efforts, I fail in students gaining systematic and product-independent basic knowledge” (WIRKLEHR_07, negative polarised item). Thus, a certain level of content validity is guaranteed. The development of the subject-specific self-efficacy scale (here for the area automated processes) was implemented as in the aforementioned way. The construct consists of items which define the individual assessment of success in teaching students certain learning area specific competences, such as the development of an algorithm to control an informatics system [13, p. 22f]. The topic-specific dealing with students was taken into account, for instance, whether the teachers feel capable to get students interested in new projects within the area of automated processes.

Eventually, the examination of the constructs (see above) was done via items. These items have been structured as a Likert scale system [12, p. 77f] ranging from "strong disagreement" (1) to "strong agreement" (6). However, Jerusalem and Schwarzer [16] used a four-level and a five-level scale, respectively. The analysis of Beierlein et. al. [6, p. 10] showed that the four-level scale lacked a differentiability of answers in the upper area of the scale. To counteract this problem and the central tendency to the middle, they suggest a six-level scale, which was chosen for this exploration. A certain number of items (not less than three) form a construct.

In addition to that, the teacher questionnaire comprises two important single items, which investigate the level of the subjective self-concept of the general teaching competency in the subject informatics, and of the subjective self-concept of the teaching competency in the area automated processes. The items are tested in the same way as described above, ranging from "very low $=1$ " to "very high $=6$ ". The item self-concept of ability in informatics includes the self-awareness of competence. Consequently, we can compare the level of the different types of self-efficacy with the subjectively perceived degree of self-concept. 
Answers on Likert scales are typically ordinally-scaled. However, for this analysis we use the Likert scale as an interval scale, because the answers, the numerical markers [12, p. 78], on our Likert scale are equidistantly displayed. Test participants should recognize the various possible answers as being equidistant. Furthermore, the results of statistical tests are falsified only marginally by the interpretation of ordinally scaled data as interval scaled data [12, p. 69]. This fact is confirmed by Allerbeck [1]. To see how far a group of test items can be taken as measurement of individual variables (here: constructs), we use Cronbach's Alpha-coefficient. The Cronbach's Alpha value was established between 0.7 and 1 (see Table ), and so the constructs can be used.

\subsection{Planning and implementation}

Until now, data collection has been taking place in the context of further teacher training, before and after five one-day to three-day in-service training programs in November 2016 as well as January, February and March of 2017. They have been attended by 58 teachers (13 female, 45 male) so far. Paper questionnaires have been used to collect data within the framework of empirical research. The following results relate to the surveys a priori to the training programs. The age range has been between 26 to 63 years. As for school types the Oberschule has been represented 34 times, the other teachers belong to either comprehensive school (seven), Realschule (six), Gymnasium (six), Hauptschule (two), schools for children with learning difficulties (two), or primary school (one). More than half of the participating teachers teach at middle schools and haven't studied computer science. They usually gain their competence to teach informatics through in-service training or autodidactically acquired know-how.

\section{First results}

Research question 1 deals with individual teacher's self-efficacy and the professional overload factor before the in-service training. The results are shown in Table 2 and Table 3. After linear transformations the item mean values from Schwarzer and Jerusalem [16] $m_{S J}$ have been transformed into $m_{\text {SItrans }}$, which are based on a six-level scale. Here, the obtained data are compared with the first results from [16, p. 73]. Their first data collection with 273 participants took place in January of 1996 (see section 2). The comparison of the data from both investigations before the programs is realised with a one-sample test. The items' mean-values of [16] are compared to each corresponding item value of the study described here. The results show that six out of the ten item values of teacher's individual self-efficacy, WIRKLEHR_01, -_02, -_04, -_05, -_07, -_09, differ significantly from the meanvalues coming from previous data $(\mathrm{p}<0.05)$. Therefore, the informatics teacher rate six self-efficacy items remarkably higher than in the previous study. In study, reported in this paper, the informatics teachers rate the self-efficacy item "I know that I will succeed in teaching the matter relevant for the examination even to the problematic students.” (WIRKLEHR_01) considerably higher, 1.15 on average on a scale of 1-6. These results suggest the assumption that the investigated teachers have a relatively high individual teacher's self-efficacy. But these findings, which have 
originated by comparing the different data sets, show only tendencies. Further investigations of teachers of different subjects are now essential to support these findings, because the data of [16] are older and based on a four-level scale.

Table 2. Item mean values of individual teacher's self-efficacy of the first survey from [16, p. 61] $\left(\boldsymbol{m}_{\boldsymbol{S} J}, \mathrm{~N}=273\right)$ and of here described survey $(\boldsymbol{m}, \mathrm{N}=58)$ as well as standard deviations $\boldsymbol{\sigma}$.

\begin{tabular}{|l|l|l|l|l|}
\hline Exemplary items & $\begin{array}{l}\boldsymbol{m}_{\text {SJ }} \\
\text { (scale: 1-4) }\end{array}$ & $\begin{array}{l}\boldsymbol{m}_{\text {SItrans }} \\
\text { (scale: 1-6) }\end{array}$ & $\begin{array}{l}\boldsymbol{m} \\
\text { (scale: 1-6) }\end{array}$ & $\boldsymbol{m}-\boldsymbol{m}_{\text {SJtrans }}$ \\
\hline WIRKLEHR_01 & $2.34(\sigma: 0.73)$ & $\mathbf{3 . 2 3}$ & $\mathbf{4 . 4 0}(\sigma: 0.83)$ & $+\mathbf{1 . 1 7}$ \\
\hline WIRKLEHR_02 & $2.97(\sigma: 0.74)$ & 4.28 & $4.73(\sigma: 0.78)$ & +0.45 \\
\hline WIRKLEHR_04 & $2.76(\sigma: 0.79)$ & 3.93 & $4.78(\sigma: 0.76)$ & +0.85 \\
\hline WIRKLEHR_05 & $2.87(\sigma: 0.78)$ & 4.12 & $4.53(\sigma: 1.10)$ & +0.41 \\
\hline WIRKLEHR_07 $7_{\text {reversed }}$ & $2.73(\sigma: 0.85)$ & 3.88 & $4.35(\sigma: 0.95)$ & +0.47 \\
\hline WIRKLEHR_09 & $3.03(\sigma: 0.74)$ & 4.38 & $4.91(\sigma: 0.75)$ & +0.53 \\
\hline
\end{tabular}

Table 3. Item mean values of professional overload of the first survey from [16, p. 73] $\left(\boldsymbol{m}_{\boldsymbol{S} \boldsymbol{J}}, \mathrm{N}\right.$ $=273)$ and of here described survey $(\boldsymbol{m}, \mathrm{N}=58)$ as well as standard deviations $\boldsymbol{\sigma}$

\begin{tabular}{|l|l|l|l|l|}
\hline Exemplary items & $\begin{array}{l}\boldsymbol{m}_{\boldsymbol{S J}} \\
\text { (scale: 1-5) }\end{array}$ & $\begin{array}{l}\boldsymbol{m}_{\text {SItrans }} \\
\text { (scale: 1-6) }\end{array}$ & $\begin{array}{l}\boldsymbol{m} \\
\text { (scale: 1-6) }\end{array}$ & $\boldsymbol{m}-\boldsymbol{m}_{\text {SJtrans }}$ \\
\hline BEL_02 & $2.77(\sigma: 0.98)$ & 3.21 & $3.36(\sigma: 1.12)$ & +0.15 \\
\hline BEL_09 & $2.36(\sigma: 0.96)$ & 2.70 & $2.40(\sigma: 0.94)$ & -0.30 \\
\hline BEL_12 & $2.17(\sigma: 0.83)$ & 2.46 & $2.02(\sigma: 0.95)$ & -0.45 \\
\hline BEL_15 & $3.10(\sigma: 1.13)$ & 3.63 & $3.47(\sigma: 1.17)$ & -0.16 \\
\hline
\end{tabular}

The item mean values of teacher's professional overload present that the informatics teachers partly feel considerably less overwhelmed. Following the results of the onesample test, one finds out that two out of the six item values of this construct (BEL_9 and BEL_12) differ significantly from the mean-values coming from previous data ( $p$ $<0.05)$. In a nutshell, the average of the item mean-values of the informatics teachers here are 2.74 and of the other teachers 2.93 on a scale reaching from 1 (equates to no professional overload) to 6 (equates to a high professional overload). This average difference is statistically not significant. This suggests that the teachers may feel marginally not professionally overloaded. However, item mean values of BEL_15 ("The time pressure I work under is too heavy.") and BEL_02 ("In my job the challenge is permanently too much to handle.”) are relatively high. This may be explained by the fact that nearly all teachers haven't studied the subject informatics and have attained their qualification to teach this subject through self-study or/and further education programs. So, they may spend more extra time on their professional qualification than other teachers, and thus may have a partly higher perceived load. This phenomenon certainly requires more investigation in further research.

To answer the second research question the results of Table should be considered. One can see that the mean values of the general informatics-specific selfefficacy, the subject-specific self-efficacy in automated processes and the general 
teaching competence in informatics are higher than the general teaching competence in the specific field of automated processes. The level of subjective competence assessments in automated processes (mean value: 3.33 ) is significantly lower than the one of self-efficacy beliefs in this area (mean value: 4.10). Thus, the teachers have trust in themselves to master informatics specific challenges with the help of their capabilities although they don't consider their teaching competences in a specific area as high. Further investigation is needed to show if there are changes in the selfefficacy and teaching competence in informatics after further training and if there are gender specific differences.

Table 4. Scale and item mean values

\begin{tabular}{|l|l|}
\hline Construct/Item & Mean value (scale: 1-6) \\
\hline General informatics-specific self-efficacy & $4.33(\sigma: 0.79)$ \\
\hline Subject-specific self-efficacy in automated processes & $4.10(\sigma: 1.03)$ \\
\hline General teaching competence in informatics & $4.13(\sigma: 0.99)$ \\
\hline General teaching competence in automated processes & $3.33(\sigma: 1.16)$ \\
\hline
\end{tabular}

The third research question is concerned with the correlation between the different constructs (see Table 4). We can describe the strength of the non-parametric Spearman's correlation using the guide that Evans [8, p. 146] suggests for the absolute value of $\mathrm{r}$. Consequently, the correlation

Table 6 shows that there are weak (0.20-0.39), moderate (0.40-0.59) and strong (0.60-0.79) significant correlations between most of the constructs. For example, a correlation value of $r=0.643$ would be a "strong positive correlation". These results support past investigations showing a correlation between self-efficacy and selfconcept (see section 2), whereas in this investigation the general informatics-specific self-efficacy does not correlate significantly with the teaching competence in automated processes. Contrary to our expectations, the perception of the professional overload seems only related to the construct subject-specific self-efficacy in automated processes and teaching competence in automated processes. This outcome contradicts the results of [15] and [9]. The results of Gebauer's inquiry lead to the conclusion that the individual teacher's self-efficacy also correlates with professional overload (see section 2, [9, p. 139]) in a negative way. For example, this relation can be found in [15] (correlations around $r=-0.50$ ). People who feel overworked in their jobs have less motivation to face new or difficult challenges. Additionally, further investigations with more participants are necessary to support the current findings. For all correlations it must be noted that due to missing data the different analyses are undertaken with responses varying from 36 to 56 participants.

Table 6 shows that there are weak (0.20-0.39), moderate (0.40-0.59) and strong (0.60-0.79) significant correlations between most of the constructs. For example, a correlation value of $\mathrm{r}=0.643$ would be a "strong positive correlation". These results support past investigations showing a correlation between self-efficacy and selfconcept (see section 2), whereas in this investigation the general informatics-specific self-efficacy does not correlate significantly with the teaching competence in automated processes. Contrary to our expectations, the perception of the professional 
overload seems only related to the construct subject-specific self-efficacy in automated processes and teaching competence in automated processes. This outcome contradicts the results of [15] and [9]. The results of Gebauer's inquiry lead to the conclusion that the individual teacher's self-efficacy also correlates with professional overload (see section 2, [9, p. 139]) in a negative way. For example, this relation can be found in [15] (correlations around $r=-0.50$ ). People who feel overworked in their jobs have less motivation to face new or difficult challenges. Additionally, further investigations with more participants are necessary to support the current findings. For all correlations it must be noted that due to missing data the different analyses are undertaken with responses varying from 36 to 56 participants

Table 5. Correlations regarding the different constructs $\left({ }^{*} \mathrm{p}<0.05\right.$, ${ }^{* *} \mathrm{p}<0.01$, other correlations are non-significant

\begin{tabular}{|l|l|l|l|l|l|}
\hline & $\begin{array}{l}\text { individual } \\
\text { teacher's } \\
\text { SE }\end{array}$ & $\begin{array}{l}\text { general } \\
\text { informatics } \\
\text {-specific } \\
\text { SE }\end{array}$ & $\begin{array}{l}\text { subject- } \\
\text { specific SE } \\
\text { in } \mathrm{AP}^{3}\end{array}$ & $\begin{array}{l}\text { teaching } \\
\text { competence in } \\
\text { informatics }\end{array}$ & $\begin{array}{l}\text { teaching } \\
\text { competenc } \\
\text { e in AP }\end{array}$ \\
\hline $\begin{array}{l}\text { individual teacher's } \\
\text { SE }\end{array}$ & 1.000 & & & & \\
\hline $\begin{array}{l}\text { general informatics- } \\
\text { specific SE }\end{array}$ & $\mathbf{0 . 4 7 6 * *}$ & 1.000 & & & \\
\hline $\begin{array}{l}\text { subject-specific SE } \\
\text { in AP }\end{array}$ & $\mathbf{0 . 3 8 7 ^ { * * }}$ & 0.260 & 1.000 & & \\
\hline $\begin{array}{l}\text { teaching competence } \\
\text { in informatics }\end{array}$ & $\mathbf{0 . 2 9 7 *}$ & $\mathbf{0 . 6 4 3 * *}$ & $\mathbf{0 . 4 4 2}^{* *}$ & 1.000 & 1.000 \\
\hline $\begin{array}{l}\text { teaching competence } \\
\text { in AP }\end{array}$ & $\mathbf{0 . 3 7 3 * *}$ & 0.296 & $\mathbf{0 . 6 1 8}^{* *}$ & $\mathbf{0 . 4 0 3 * *}$ & \\
\hline $\begin{array}{l}\text { professional } \\
\text { overload }\end{array}$ & -0.115 & -0.223 & $\mathbf{- 0 . 3 9 3 * *}$ & -0.214 & $\mathbf{- 0 . 3 5 5 ^ { * * }}$ \\
\hline
\end{tabular}

\section{Conclusion}

One important research result is that the informatics teachers perceive that the job is challenging and much to handle (item mean value: 3.36 ) and the time pressure they work under is heavy (item mean value: 3.47), but their teaching self-efficacy (construct mean value: 4.54) and their general informatics-specific self-efficacy (construct mean value: 4.33) are relatively high. Consequently, I assume that they might be able to spend more extra time, than other teachers, on improving their professional qualifications before they feel too overworked. Therefore, one should offer the chance to participate in in-service training programs (one day to three days training). In the process, the themes and levels (beginner and advanced teachers) should be taken into account to avoid teachers feeling overburdened. This is one way to enable many teachers at secondary schools, who teach informatics as nonspecialists, to improve their qualification in teaching the subject informatics. Then

2 Self-efficacy is abbreviated as "SE" in this table.

3 Automated processes is abbreviated as "AP" in this table. 
these teachers can provide their students even better with sustainable skills to deal with information technology responsibly. Further on, it must be investigated whether in-service training programs (one to three days) influence the level of teacher's selfefficacy. And if so, the factors which make training programs work successfully must be found out. This is an important aspect, because teachers with a high level of teacher's self-efficacy influence the quality of classroom processes in a very positive way (cf. chapter 2).

\section{References}

1. Allerbeck, K.R.: Messniveau und Analyseverfahren - Das Problem strittiger Intervallskalen. Zeitschrift für Soziologie (3), 199-214 (1978).

2. Bandura, A.: Self-efficacy: Toward a unifying theory of behavioral change. Psychological Review 84(2), 191-215 (1977).

3. Bandura, A.: Exercise of personal and collective efficacy in changing societies. In: Bandura, A. (eds.) Self-efficacy in Changing Societies, pp. 1-45. Cambridge University Press, New York (1995).

4. Bandura, A.: Self-efficacy: The exercise of control. Freeman, New York (1997).

5. Banoglu, K., Vanderlinde, R., Yildiz, R.: Professional self-efficacy scale for information and computer technology teachers: validity and reliability study. ANTHROPOLOGIST 20(1-2), 22-32 (2015).

6. Beierlein, C., Kovaleva, A., Kemper, C.J., Rammstedt, B.: Ein Messinstrument zur Erfassung subjektiver Kompetenzerwartungen: Allgemeine Selbstwirksamkeit Kurzskala (ASKU). GESIS, Mannheim (2012).

7. Bong, M., Skaalvik, E.M.: Academic self-concept and self-efficacy: How different are they really? Educational Psychology Review 15(1), 17-30 (2003).

8. Evans, J. D.: Straightforward statistics for the behavioral sciences. Brooks/Cole Publishing, Pacific Grove, CA (1996).

9. Gebauer, M.M.: Determinanten der Selbstwirksamkeitsüberzeugung von Lehrenden. Schulischer Berufsalltag an Gymnasien und Hauptschulen. Springer VS, Wiesbaden (2013).

10. Gibson, S., Dembo, M.H.: Teacher efficacy: A construct validation. Journal of Educational Psychology 76(4), 569-582 (1984).

11. Holzberger, D., Philipp, A., Kunter, M.: How teachers' self-efficacy is related to instructional quality: A longitudinal analysis. Journal of Educational Psychology 105(3), 774-786 (2013).

12. Hussy, W., Schreier, M., Echterhoff, G.: Forschungsmethoden in Psychologie und Sozialwissenschaften, 2., überarbeitete Auflage. Springer, Berlin Heidelberg (2013).

13. Niedersächsisches Kultusministerium: Kerncurriculum für die Schulformen des Sekundarbereichs I Schuljahrgänge 5 - 10 Informatik, Niedersachsen. Unidruck, Hannover (2014).

14. Santos, A., Pedro, N.: The relationship between teachers' training, personal sense of efficacy and ict integration: Analysing its strength and stability. In: ICICTE2012 Proceedings of International Conference on Information Communication Technologies in Education. pp. 343 - 354. ICICTE, Rhodes (2012).

15. Schmitz, G.S., Schwarzer, R.: Selbstwirksamkeitserwartung von Lehrern: Längsschnittbefunde mit einem neuen Instrument. Zeitschrift für Pädagogische Psychologie 14, 12-25 (2000). 
16. Schwarzer, R., Jerusalem, M.: Skalen zur Erfassung von Lehrer- und Schülermerkmalen. Dokumentation der psychometrischen Verfahren im Rahmen der Wissenschaftlichen Begleitung des Modellversuchs Selbstwirksame Schulen. Berlin (1999).

17. Shavelson, R.J., Hubner, J.J., Stanton, G.C.: Self-concept. Validation of construct interpretations. Review of Educational Research 46(3), 407-441 (1976).

18. Zee, M., Koomen, H.M.Y.: Teacher Self-Efficacy and Its Effects on Classroom Processes, Student Academic Adjustment, and Teacher Well-Being: A Synthesis of 40 Years of Research. Review of Educational Research 86(4), 981-1015 (2016). 